Arhe XVII, 34/2020

UDK 16 Aristoteles

DOI https://doi.org/10.19090/arhe.2020.34.205-218

Originalni naučni rad

Original Scientific Article

\author{
KRISTINA TODOROVIĆ ${ }^{1}$ \\ Univerzitet u Novom Sadu, Filozofski fakultet
}

\title{
KAPADOKIJSKI OCI I ARISTOTELOV ORGANON
}

Sažetak: Autor u ovom istraživanju nastoji da ispita koja je uloga Aristotelovog Organona u teološkim učenjima Kapadokijskih Otaca. Cilj ovog rada je da se pokaže da su se Kapadokijski Oci služili Aristotelovim pojmovima prve i druge suštine, u svrhu odbrane zvaničnih učenja crkve od suprotstavljenih učenja koja su se smatrala jeretičkim. Iako se Kapadokijski teolozi u svojim radovima služe filozofskim pojmovima, to nikako ne znači da oni odstupaju od izvornog hrišćanskog učenja.

Ključne reči: Aristotel, Bog, ipostas, Kapadokijski Oci, suština

\section{UVOD}

Kapadokijski Oci (sv. Vasilije Veliki, sv. Grigorije Bogoslov i sv. Grigorije Niski), koji su živeli u IV veku, imali su zadatak da sačuvaju zvanično učenje hrišćanske crkve od raznih suprotstavljenih učenja koja su se smatrala jeretičkim. Često se navodi da su pomenuta jeretička učenja bila inspirisana Aristotelovom filozofijom, kao i to da su se, upravo zbog uvođenja filozofskih pojmova, udaljila od izvornih crkvenih učenja. ${ }^{2}$ Ove tvrdnje će za naše istraživanje biti veoma interesantne, jer nameravamo da u ovom radu pokažemo kako su Kapadokijski Oci takođe dobro poznavali Aristotelov Organon, koji im je

\footnotetext{
${ }^{1}$ E-mail adresa autorke: tina.todorovic@live.com

2 Popović, Radomir, Vaseljenski sabori, Biblioteka Svečanik: Hrišćanska misao, Beograd, 1997, str. 14.
} 
služio kao oruđe u borbi protiv jeresi. Napominjemo da naša namera nije u tome da tvrdimo da se učenja Kapadokijskih Otaca mogu poistovetiti sa filozofskim učenjima. Teza kojom ćemo se voditi u našem radu jeste da su kapadokijski teolozi, iako su koristili filozofske pojmove u svrhu objašnjenja hrišćanskih učenja, ipak ostajali dosledni tom učenju.

Kako bismo to pokazali, najpre ćemo razmotriti dva ključna pitanja. Prvo pitanje se tiče mogućnosti saznanja Boga, a drugo, koje proizlazi iz prvog, tiče se shvatanja Boga kao istovremeno jednog i trojičnog, što je ujedno i bilo predmet sukoba crkvenih i jeretičkih učenja. Prvo poglavlje (Mogućnost saznanja Boga), ima za cilj da ukratko pruži uvid u to da su kapadokijski teolozi smatrali da su naše saznajne mogućnosti ograničene kada je reč o saznanju Boga. Bog prevazilazi naše saznajne moći, ali nam se na neki način ipak otkriva (kao što nam govori Sveto Pismo). Otuda proizlazi potreba da se objasni na koji to način za Boga tvrdimo da je jedan i trojičan, što ćemo detaljnije razmatrati u drugom poglavlju (Bog kao jedan i trojičan). Potom ćemo se u sledećem poglavlju (Vaseljenski Sabori i borba protiv jeresi) ukratko osvrnuti na istorijske okolnosti, kako bismo prikazali od kolike su važnosti bili problemi o kojima govorimo. Crkva je sazvala čak dva Vaseljenska Sabora na kojima su se rešavali sukobi sa arijanskim i monarhijanskim jeretičkim učenjima. Videćemo da pomenuta jeretička učenja nikako nisu mogla da pomire ove dve istine o Bogu, da je on istovremeno jedan i trojičan. U poslednjem poglavlju (Suština i ipostas), preciziraćemo koja je tačno veza između Aristotelovog Organona i učenja Kapadokijskih Otaca. Videćemo koju su tačno ulogu imali Aristotelovi pojmovi prve i druge suštine (supstancije) u pokušajima da se obrazloži na koji način treba tumačiti spornu tvrdnju da je Bog istovremeno jedan i trojičan. Zaključak ćemo iskoristiti da sumiramo rezultate naših istraživanja, kao i da pokažemo koja to nova pitanja mogu proizaći iz ovih razmatranja.

\section{MOGUĆNOST SAZNANJA BOGA}

Pre nego što se upustimo u razmatranje odnosa Aristotelovog Organona i učenja Kapadokijskih Otaca, smatramo da je od velike 
važnosti najpre razjasniti šta to Kapadokijski Oci misle o mogućnosti saznanja Boga. Sv. Vasilije Veliki nam govori o tome da je Božija suština potpuno nesaznatljiva, jer ona prevazilazi naše saznajne mogućnosti. ${ }^{3}$ Kada Vasilije Veliki kaže da je Božija suština nesaznatljiva, to znači da mi ne možemo znati šta Bog jeste. Međutim, Bog nam se na neki način ipak pokazuje, zbog čega se kaže da je On: „,istovremeno i nepoznatljiv po suštini Svojoj i poznatljiv po javljanjima i delovanjima svojim u svetu $\mathrm{i}$ istoriji." ${ }^{4}$

S obzirom na to, mi možemo reći da nekakvo saznanje o Bogu ipak postoji, samim tim je moguć i govor o Bogu. Međutim, govor o Bogu je važno razumeti na pravi način. Kapadokijski Oci smatraju da je bitno uvek imati na umu da ono o čemu se govori (Bog), ujedno prevazilazi jezik kojim se o njemu govori, ali da se, ipak, tim jezikom dolazi do delimične spoznaje Boga (onoliko koliko to naš um može). ${ }^{5}$ Zbog toga će sv. Vasilije govoriti o preplitanju pozitivnih (katafatičkih) i negativnih (apofatičkih) tvrdnji o Bogu, koje će kasnije sv. Dionisije Areopagit detaljnije razmatrati u V veku. ${ }^{6}$ Dakle, kao što nam to navodi Lurje (M. V. Lurie): ,pozitivne tvrdnje, kao i negacije u vezi sa Bogom u sebi sadrže, premda i nepotpuno, ali ipak realno prisustvo Boga u nama.“7 Ovo naizgled kontradiktorno shvatanje mogućnosti saznanja Boga, Kapadokijski Oci su pokušali da objasne razlikovanjem - za nas nespoznatljive Božije suštine, od Božijih energija (delovanja u svetu) za koja znamo, ${ }^{8}$ među kojima se ubraja i Sveto Pismo. Znamo da Sveto Pismo obiluje različitim opisima i imenima koji se jednako i u celosti odnose na Boga, zbog čega su Vasilije Veliki, a kasnije i Grigorije Bogoslov i Grigorije Niski, na isti način tvrdili da je Bog istovremeno nesaznatljiv i saznatljiv, neizreciv i izreciv. ${ }^{9}$ Ovaj problem najbolje je

${ }^{3}$ Jevtić, Atanasije, Patrologija, druga knjiga, Bratstvo sv. Simeona Mirotočivog, 1997, str. 98.

${ }^{4}$ Isto, str. 99.

${ }_{6}^{5}$ Isto.

${ }^{6}$ Lurje, V. M, Istorija vizantijske filozofije, Izdavačka knjižarnica Zorana Stojanovića, Sremski Karlovci, Novi Sad, 2010., str. 91.

${ }^{7}$ Isto.

${ }^{8}$ Isto, str. 90.

${ }^{9}$ Jevtić, Atanasije, Patrologija, druga knjiga, str. 98, 99. 
izrazio sv. Grigorije Bogoslov u jednoj pesmi koju je nazvao Himna Bogu, a koja glasi:

O Onostrani svemu, jer kako Te drugo nazvati?

Kako će reč Te hvaliti? Jer nisi nijednom rečju izreciv.

Kako ce um Te shvatiti? Jer nisi nijednim umom shvatljiv.

Jedini si Neiskaziv, jer si rodio sve govorljivo.

Jedini si Nepoznatljiv, jer si rodio sve poznatljivo.

Sve Te i govoreće i nemušto priziva.

Sve Te i misleće i nemisleće hvali.

Jer zajedničke želje, zajednički bolovi svih

oko Tebe su. Tebi se sve moli, i Tebi sve i sva

znak Tvoj shvativši himnu ćuteću peva.

Tobom Jedinim sve postoji, i Tobom se sve skupa kreće.

I cilj si svega Ti, i Jedan, i Sve, i Niko;

ne da si Jedan, ne da si Sve. Sveimeniti, kako Te nazvati, jedinoga Bezimenog? A iznad pokrova oblaka

koji ce um u Nebo prodreti? Milostiv budi,

O Onostrani svemu, jer kako Te drugo nazvati? ${ }^{10}$

Kao što vidimo u prethodnoj pesmi, Kapadokijski Oci su imali zadatak da objasne na koji način treba razumevati tvrdnje da je Bog istovremeno ono misleće i nemisleće, sveimeno i bezimeno... Identični problemi biće prisutni i mnogo posle njih, kako u hrišćanskim, tako i u filozofskim učenjima neoplatonizma. Navedena pesma bila je od velikog značaja jer su se istraživači sukobljavali oko toga da li da je njen autor pomenuti Dionisije Areopagit ili filozof Proklo. ${ }^{11}$

Do sada smo govorili o mogućnosti saznanja Boga u učenjima Kapadokijskih Otaca kako bismo na pravi način mogli da pristupimo i drugom pitanju, pitanju o razumevanju Boga kao jednog i trojičnog, što će biti tema našeg narednog poglavlja.

${ }^{10}$ Jevtić, Atanasije, Patrologija, druga knjiga, str. 120, 121.

${ }^{11}$ Bajervaltes Verner, Platonizam u hrišćanstvu, Akademska knjiga, Novi Sad, 2009, str. 105, 106. 


\section{BOG KAO JEDAN I TROJIČAN}

Molitva Simbol vere postala je neizostavni deo crkvenih obreda Liturgije (Evharistije) i Krštenja. Prisustvujući ovim obredima, mi danas možemo čuti reči: „Verujem u jednoga Boga, Oca, Svedržitelja, Tvorca Neba i zemlje i svega vidljivog i nevidljivog." ${ }^{12}$ Dakle, hrišćani će se složiti sa tim da postoji samo jedan Bog, stvoritelj svega što postoji. Međutim, oni jednako priznaju za istinitu tvrdnju da je Bog istovremeno i trojičan (Otac, Sin i Sveti Duh). Zbog toga, u nastavku pomenute molitve se govori sledeće: „I u jednoga Gospoda Isusa Hrista, Sina Božijeg... jednosušnog sa Ocem, kroz koga je sve postalo;"13 Naravno, u ovoj molitvi se pored Sina pominje i Sveti Duh: „I u Duha Svetog, Gospoda životvornog, Koji od Oca ishodi, Koji se sa Ocem i Sinom zajedno poštuje i slavi..."14 Pitanje odnosa ovih naizgled protivrečnih tvrdnji, da je Bog jedan i trojičan, bilo je veoma značajno u IV veku, jer su teolozi tog doba različito tumačili njihova značenja. Da bi objasnili kako treba shvatiti ove tvrdnje, teolozi IV veka (kako oni koji su branili zvanična učenja crkve, pa tako i oni čija su se učenja smatrala jeretičkim) koristili su pojmove grčke filozofije. Ono što mi ovim istraživanjem želimo da pokažemo, jeste uloga zbirke Aristotelovih logičkih spisa Organon u teološkim raspravama iz IV veka.

Kao što smo na samom početku ustanovili, kapadokijski teolozi su svesni da se predmet njihovog proučavanja (Bog) ne može $u$ potpunosti izraziti rečima, kao i toga da nam pozitivne i negativne tvrdnje o Bogu ipak pružaju nekakvo nesavršeno saznanje. Zbog toga, teolozi se često izražavaju u formi logičkih protivrečnosti. ${ }^{15}$ Upravo tako treba tumačiti rečenice da je Bog istovremeno saznatljiv i nesaznatljiv, izreciv $\mathrm{i}$ neizreciv, jedan i trojičan... Dakle, možemo reći da se svaka od dve suprotne tvrdnje jednako odnosi na Boga, upravo u svetlu priznavanja jedinstva potvrdnog i odričnog načina govora o Bogu. Međutim, nisu se svi teolozi tog doba slagali sa ovim tvrdnjama, zbog čega ćemo u

\footnotetext{
${ }^{12}$ Manastir Rukumija, Pravoslavni molitvenik, Kolor Pres, Lapovo, 2009, str. 13.

13 Isto.

14 Isto.

${ }^{15}$ Lurje, V. M, Istorija vizantijske filozofije, str. 65.
} 
narednom poglavlju pokušati da ukratko prikažemo razloge njihovih nesuglasica.

\section{VASELJENSKI SABORI I BORBA PROTIV JERESI}

Kao što smo u prethodnom poglavlju rekli, različita tumačenja Boga kao jednog i trojičnog prouzrokovala su nastanak brojnih učenja $\mathrm{u}$ IV veku koja hrišćanska crkva proglašava jeretičkim. Nama će u fokusu istraživanja biti dve struje takozvanih jeretičkih učenja, monarhijanizam i arijanizam, upravo zbog toga što su u raspavama sa njima, a braneći zvanična učenja crkve, teolozi koristili pojmove iz Aristotelovog Organona.

Sveti Vasilije Veliki jednako je vrednovao pismeno (Sveto Pismo), kao i usmeno predanje koje dolazi od apostola. Pismeno i usmeno predanje, podrazumevaju veru u Boga kao Svetu Trojicu (Oca, Sina i Svetoga Duha). Dakle, Vasilije je smatrao da je ispravno tvrditi da je Bog istovremeno jedan i trojičan. ${ }^{16}$ Ovom Vasilijevom stavu suprotstavljaju se monarhijanska učenja koja su: „..poricala stvarno postojanje Svete Trojice i svodila shvatanje Boga na usko shvaćeni, sterilni judejski monoteizam, poričući pri time osnovnu blagovest Jevanđelja o Bogu Ocu i Sinu i Svetome Duhu. ${ }^{17}$ Reč je o tome da su monarhijanska učenja propovedala ideju da je Bog zapravo jedan, a da su tri lica samo maske, odnosno modusi tog jednog. ${ }^{18}$ Sa druge strane, Sveti Vasilije insistira na razlkovanju tri realno postojeće ličnosti, odnosno tri zasebne realnosti, zbog čega uvodi filozofski pojam ipostasi

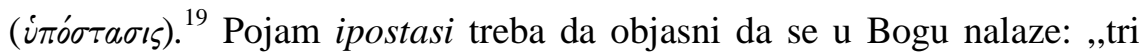
stvarno postojeće konkretne Ličnosti, jedinstvene, neponovljive, ni na šta drugo svodive. ${ }^{20}$ Ovaj pojam ćemo analizirati u poglavlju koje sledi, jer nam je cilj da najpre osvetlimo okolnosti koje su doprinele tome da se

\footnotetext{
${ }^{16}$ Jevtić, Atanasije, Patrologija, druga knjiga, str. 93.

${ }^{17}$ Isto, str. 95.

${ }^{18}$ Isto.

${ }^{19}$ Isto.

${ }^{20}$ Isto.
} 
uopšte i javi potreba za uvođenjem filozofskih pojmova u borbi za očuvanjem izvornih crkvenih učenja.

Do sada smo videli da je jedan od problema bio sačuvati predstavu o jedinstvenosti Boga, a da se pri tome njegova tri lica ne doživljavaju samo kao maske, modusi jednog te istog, kao što to govore monarhijanska učenja, već kao tri posebne realnosti. Sa druge strane, pojavila su se i arijanska učenja koja su tvrdila potpuno suprotno od monarhijskih: „Ta jeres je padala u drugu krajnost, u jelinsku zabludu politeizma, jer je Hrišćansku Trojicu shvatala kao tri posebna i razdeljena božanska ili polubožanska bića, tri potpuno samostalne, različite i međusobno sasvim neslične prirode jerarhijski međusobno niže i jedna drugoj podređene i podčinjene." ${ }^{21}$ Primetimo da se u citatu pominje pojam prirode. Pre nego što nastavimo sa daljom analizom moramo napomenuti da su Kapadokijski Oci koristili sinonimno pojmove priroda

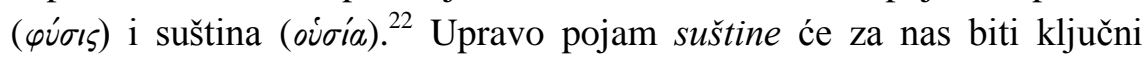
pojam koji direktno povezuje Aristotelov Organon i učenja pomenutih Kapadokijskih Otaca.

Kapadokijski teolozi su smatrali da monarhijanska i arijanska učenja nisu u skladu sa pismenom i usmenom tradicijom crkve. Videli smo da su monarhijanska učenja težila očuvanju jedinstvenosti Boga zanemarujući ideju o trojičnosti, dok su arijanska insistirala na postojanju tri zasebne božije suštine, što je podsećalo na politeistička shvatanja Boga. Zbog sukoba sa monarhijanskim i arijanskim učenjima, crkva je sazvala dva Vaseljenska Sabora. Prvi se održao u Nikeji 325. godine, a drugi u Konstantinopolju 381. godine. ${ }^{23}$ Kako bi objasnili način na koji se Bog može razumeti istovremeno kao jedan i trojičan, teolozi će uvesti razliku između pojmova suštine, tačnije jednosušnosti (ómoovoıs) i

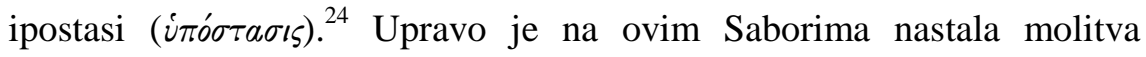
Simbol vere o kojoj smo govorili na početku rada, a koja se i danas neizostavan deo svetih službi Krštenja i Evharistije (Liturgije). ${ }^{25}$

\footnotetext{
${ }^{21}$ Isto, str. 96.

${ }^{22}$ Lurje, V. M, Istorija vizantijske filozofije, str. 88.

${ }^{23}$ Isto, str. 67. i 70.

${ }^{24}$ Isto, str. 67.

25 Isto.
} 


\section{SUŠTINA I IPOSTAS}

Hrišćanski teolozi su preuzeli pojam suštine (ovoía) iz Aristotelovog Organona, tačnije iz spisa Kategorije. Aristotel razlikuje deset kategorija, odnosno najopštijih pojmova, a to su: suština (supstancija), kvalitet, kvantitet, odnos, mesto, vreme, položaj, posedovanje, delanje i trpljenje. ${ }^{26}$ Prva kategorija je specifična u odnosu na ostale, jer, kada je reč o suštini (supstanciji), Aristotel razlikuje prve od drugih suština. ${ }^{27}$

Kako bismo razumeli razliku između prvih i drugih suština, najpre ćemo videti na koji način ih Aristotel definiše. Za prvu suštinu (supstanciju) Aristotel kaže: „Supstancija, u najsvojstvenijem, i prvom, i glavnom smislu, jeste ono što nije ni afirmirano o jednom subjektu niti je u jednom subjektu - kao, na primer, jedan određeni čovek ili jedan određeni konj. “28 Dakle, kao što vidimo, prve suštine se odnose na pojedinačna bića, dok se druge suštine odnose na ono opšte, odnosno ono čime ta bića možemo odrediti: „Druge supstancije nazivaju se rodovi u kojima su sadržane supstancije uzete u prvom smislu, a rodovima treba dodati i vrste ovih rodova. Tako na primer, jedan određeni čovek spada u rod čoveka, a vrsta ovog roda je životinja. Ove (poslednje) supstancije zovu se „druge“, - kao što su na primer, čovek i životinja.“29 Kao što vidimo, druge suštine (supstancije), predstavljaju rod i vrstu pomoću kojih mi zapravo određujemo značenje prvih suština. Aristotel kaže: „Jer (od svih predikata), oni (rodovi i vrste) jedini objašnjavaju prvu supstanciju po njenom značenju. Naime, ako se želi objasniti šta je jedan određeni čovek, i ako se to učini pomoću roda ili vrste, - daće se objašnjenje njegove svojstvenosti...“30 Prema Aristotelovom mišljenju, mi saznajemo šta neka stvar jeste, odnosno, koja je njena definicija, onda kada odredimo rod i vrstu kojoj ta stvar pripada. ${ }^{31}$ Već sada možemo

\footnotetext{
${ }^{26}$ Aristotel, Organon, Kultura, Beograd, 1970, str. 7.

${ }^{27}$ Isto.

${ }^{28}$ Isto, str. 8.

${ }^{29}$ Isto.

${ }^{30}$ Isto, str. 10.

${ }^{31}$ Isto, str. 326, 327.
} 
videti da se Aristotelovo razumevanje saznanja ne može primeniti na saznanje Boga, onako kako su to Kapadokijski Oci već utvrdili. Ne postoji nikakav rod i vrsta pomoću kojih možemo Boga definisati, jer On, u tom smislu, prevazilazi naše saznajne mogućnosti. Suština je u tome da se do Božijeg postojanja dolazi verom, međutim, sv. Vasilije kaže da je u redu tvrditi da se do toga može doći i saznanjem, sve dok se imaju na umu ograničenja ljudskog saznanja u odnosu na Boga. ${ }^{32}$

Upravo zbog poštovanja ograničenja mogućnosti saznanja Boga, teolozima koju su branili izvorna učenja crkve zasmetalo je učenje sveštenika Arija (po kome je arijanizam i dobio ime), kao i njegovog naslednika Evnomija, zbog kojih su se i održala prva dva Vaseljenska Sabora. Naime, tvrdi se da je Arije, koristeći se Aristotelovom filozofijom, došao do zaključka da Bog mora biti jedan i apsolutan - kao Otac, a da je Sin (Isus Hrist), stvoren kasnije, zbog čega nema istu suštinu kao Otac. ${ }^{33}$ Arijevo učenje proširio je njegov učenik Evnomije, koji tvrdi da se Božija suština (suština Oca) može odrediti kao nerođenost, a pošto je Sin rođen, onda je njegova suština drugačija od suštine Oca. ${ }^{34}$ Evnomijeva učenja su zasnovana na tome da je Sin nepodoban (nesličan) Ocu, odnosno da je Sin inosušan - kao što smo već i rekli, da je druge suštine u osnosu na Oca. ${ }^{35}$ Oba Vaseljenska Sabora završila su se osudom Arijevog i Evnomijevog učenja, a da bi sačuvali izvornu predstavu o odnosu Boga Oca i Boga Sina, teolozi su uveli pojam jednosušnosti (ómoovंoıs), što znači da oni imaju jednu istu suštinu. ${ }^{36}$

Sa druge strane, postojala je opasnost da se ovaj pojam jednosušnosti razume na takav način da između Oca i Sina nema nikakve realne razlike, kao što su tvrdila već pomenuta monarhijanska učenja.

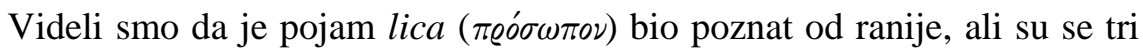
Božija lica tumačila samo kao maske, modusi jednog istog. Zbog toga je

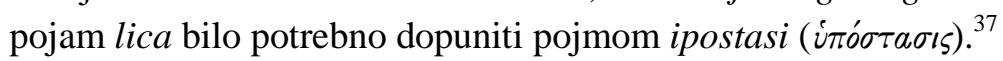

32 Jevtić, Atanasije, Patrologija, druga knjiga, str. 100.

${ }^{33}$ Popović, Radomir, Vaseljenski sabori, str. 14, 15.

${ }^{34}$ Lurje, V. M, Istorija vizantijske filozofije, str. 73.

${ }^{35}$ Isto, str. 72.

${ }^{36}$ Isto, str. 71.

${ }^{37}$ Zizjulas, Jovan, Od maske do ličnosti, u: Bogoslovlje, Beograd, 1985, str. 22. 
Dakle, da bi se sačuvala razlika između tri lica jednoga Boga,

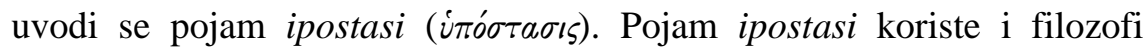
neoplatonizma kada govore o stepenima emanacije jednog, međutim, iako svoje poreklo ima u grčkoj filozofiji, ovaj pojam dobija potpuno novo značenje u okvirima hrišćanskog učenja. ${ }^{38}$

Iako se filozofska i hrišćanska učenja ne mogu poistovetiti, među njima postoji sličnosti u tome što se i jedna i druga koriste identičnim pojmovima. Međutim, ti pojmovi imaju drugačiji smisao, u zavisnosti od toga da li se posmatraju u filozofskom ili hrišćanskom kontekstu. Zbog toga, ostaje nam da objasnimo koja je tačno veza između teoloških pokušaja objašnjenja problema jedinstva i trojičnosti Boga i Aristotelovog Organona.

Sva Trojica Kapadokijskih Otaca identično razumevaju pojmove suštine i ipostasi. ${ }^{39} \mathrm{U}$ početku su teolozi koristili ove pojmove sinonimno, a zatim je sv. Vasilije Veliki, pomoću Aristotelovog Organona, objasnio da ih je ipak potrebno razlikovati. ${ }^{40}$ Pod pojmom suštine, Vasilije podrazumeva ono što je za Aristotela bila druga suština, kao što Lurje kaže: „Zato je u patristici termin suština prestao da zahteva preciziranja da li se ima u vidu prva ili druga suština... Tako pojam suštine u hrišćanskom bogoslovlju ostaje aristotelovski.“41 $\mathrm{U}$ svetlu prethodnih istraživanja, smatramo da ovom rečenicom Lurje nije mislio da je ovaj pojam bukvalno ostao aristotelovski. Smatramo da je ovde reč o tome da pojam druge suštine ima istu ulogu u odnosu na pojam ipostasi, kao što je kod Aristotela imao u odnosu na prvu suštinu. Preciznije rečeno, kao što kod Aristotela druge suštine predstavljaju ono „opšte“, tako i u hrišćanskom smislu suština predstavlja ono što je, uslovno rečeno, zajedničko za Svetu Trojicu. Sa druge strane, ono pojedinačno (različita lica: Otac, Sin, Sveti Duh) će predstavljati pojam ipostasi: „Pojam prve suštine Vasilije Veliki i Grigorije Bogoslov zamenjuju pojmom ipostasi,

\footnotetext{
${ }^{38}$ Lurje, V. M, Istorija vizantijske filozofije, str. 69.

${ }^{39}$ Isto, str. 81 .

${ }^{40}$ Isto.

${ }^{41}$ Isto.
} 
ali to čine tako da značenje hrišćanskog termina daleko prevazilazi aristotelovsku definiciju. “42

Rekli smo da je pojam lica dopunjen pojmom ipostasi kako bi se izbegao rizik da se tri lica Boga tumače kao nekakve maske, modusi jednog $^{43}$, kao što su tvrdile monarhijanske jeresi. Umesto toga, pojam ipostasi ukazuje na postojanje tri zasebne realnosti. ${ }^{44}$ Tako su u Bogu suština i ipostasi u međusobnom odnosu. Grigorije Bogoslov određuje ipostasi kao: ,,svojevrsne rezervoare suštine““ ${ }^{45}$

Pojedini teolozi, kao što je Jovan Zizjulas (John Zizioulas), tvrde da je tumačenje Božije suštine kao onoga što pruža jedinstvo Božije - i time predstavlja primaran način postojanja Boga, a da On tek na osnovu toga postoji i kao Trojica, preovladalo na hrišćanskom Zapadu. ${ }^{46}$ Međutim, Zizjulas takođe tvrdi da se na hrišćanskom Istoku ovaj odnos tumači drugačije: „Za Oce Istoka jedinstvo Božje, jedan Bog... ne čini jedna suština Božja nego ipostas, to jest ličnost Oca. Jedan Bog nije jedna suština nego jedan Otac, koji je 'uzrok' rođenja Oca, i ishođenja Duha svetoga. Dakle, ontološko načelo se uzvodi na ličnosti. “47 Ovakva zapažanja bi mogla biti tema nekog zasebnog istraživanja, međutim, mi smo se u ovom radu fokusirali na pokušaj objašnjenja kako treba shvatiti tvrdnje da je Bog istovremeno jedan i trojičan, a ne toliko na sam odnos suštine i ipostasi u Bogu.

Nakon rasprava koje su vođene na Vaseljenskim Saborima, nastala je molitva Simbol vere, koja predstavlja krajnji rezultat dogovora koji je postignut među teolozima koji su branili izvorna učenja crkve. Otac, Sin i Sveti Duh se istovremeno tumače kao jedna realnost, iste suštine, zbog čega se i kaže da je Sin jednosušan Ocu. Iako se u molitvi nigde ne spominje direktno, isto važi i za Sveti Duh, o čemu su posebno Kapadokijski Oci pisali u svojim delima. ${ }^{48}$ Sa druge strane, Bog je takođe

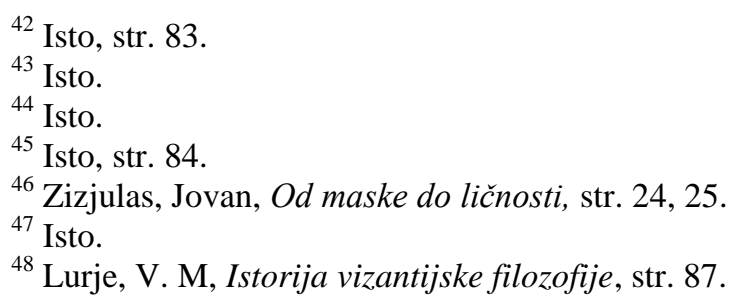


i trojičan, odnosno u njemu se takođe razlikuju tri posebne realnosti, lica ili ipostasi: „Tri ipostasi su tri samostalne realnosti i zato ne može biti govora o modalizmu. Ali one su jednosušne, odnosno pripadaju jednoj istoj realnosti - božanskoj suštini, te zato ne može biti govora o politeizmu.“49

\section{ZAKLJUČAK}

U želji da ispitamo u kakvoj su vezi učenja Kapadokijskih otaca i Aristotelovog Organona, započeli smo naše istraživanje razmatranjem mogućnosti saznanja Boga. Videli smo da Kapadokijski Oci insistiraju na, sa jedne strane, nesaznatljivosti Boga, čija suština prevazilazi naše saznajne mogućnosti. Sa druge strane, mi smo govorili o tome da nam je Bog ipak nekako poznat. Takođe smo videli da je pitanje mogućnosti saznanja Boga usko povezano sa našim tumačenjem Boga kao istovremeno jednog i trojičnog. Da bi objasnili na koji način treba shvatiti ovu tvrdnju, Kapadokijski Oci su koristili Aristotelov Organon, konkretno - učenje o prvoj i drugoj suštini koje se nalazi u spisu Kategorije, kao inspiraciju. Tako su filozofski pojmovi suštine i ipostasi dobili novo značenje i ulogu u okviru hrišćanskog učenja. Pojam suštine koji je zajednički za sva tri lica, treba da objasni da su Otac, Sin i Sveti Duh u stvari jedno. Sa druge strane, to jedno se takođe sastoji iz tri ipostasi, tri zasebno postojeće realnosti Boga.

Tvrdnjom da je Božija suština zapravo nerođenost, Evnomije zagovara ideju da je ona (suština) ipak saznatljiva, što se nikako ne slaže sa učenjima Kapadokijskih Otaca ${ }^{50}$ Rekli smo da je Bog nespoznatljiv po svojoj suštini, ali da je spoznatljiv po svojim delovanjima u svetu (energijama). ${ }^{51}$ Međutim, ono što smo propustili da preciziramo u samom radu, jeste da se pomenute energije dovode u vezu sa ipostasima Božijim. Ipak, napomenuli smo da se Sveto Pismo takođe ubraja u jedno od Božijih delovanja u svetu, jer, između ostalog, sadrži imena Božija za

\footnotetext{
${ }^{49}$ Isto, str. 68.

${ }^{50}$ Isto, str. 88.

${ }^{51}$ Isto, str. 90 .
} 
koja se smatra da su osobine Božijih ipostasi. ${ }^{52} \mathrm{Na}$ taj način: „Energije Božije, budući da su i same Bog, objavljuju nam Njegova imena, čine Ga spoznatljivim, premda suština (priroda) Božija pri tome ostaje nespoznatljiva." ${ }^{\text {"53 }}$ Time dolazimo do zaključka da nikada ne možemo saznati šta Bog jeste, već se naše saznanje tumači kao ličnosni odnos, to jest poznavanje Božijih ličnosti (ispostasi), odnosno delovanja (energija) u svetu. Ovakvi zaključci će kasnije biti predmet rasprave hrišćanskog Istoka i Zapada, odnosno mimoilaženja u razumevanju mogućnosti saznanja Boga ${ }^{54}$, što takođe može biti tema zasebnog istraživanja.

\section{LITERATURA}

Aristotel, Organon, Kultura, Beograd, 1970.

Bajervaltes Verner, Platonizam u hrišćanstvu, Akademska knjiga, Novi Sad, 2009.

Jevtić, Atanasije, Patrologija, druga knjiga, Bratstvo sv. Simeona Mirotočivog, 1997.

Lurje, V. M, Istorija vizantijske filozofije, Izdavačka knjižarnica Zorana Stojanovića Sremski Karlovci, Novi Sad, 2010.

Manastir Rukumija, Pravoslavni molitvenik, Kolor Pres, Lapovo, 2009.

Popović, Radomir, Vaseljenski sabori, Biblioteka Svečanik: Hrišćanska misao, Beograd, 1997.

Zizjulas, Jovan, Od maske do ličnosti, u: Bogoslovlje, Beograd, 1985.

\footnotetext{
${ }^{52}$ Isto, str. 89.

${ }^{53}$ Isto, str. 90.

${ }^{54}$ Isto.
} 


\author{
KRISTINA TODOROVIĆ \\ University of Novi Sad, Faculty of Philosophy
}

\title{
CAPPADOCIAN FATHERS AND ARISTOTLE'S ORGANON
}

\begin{abstract}
In this research, the author tries to examine the role of Aristotle's Organon in the theological teachings of the Cappadocian Fathers. The aim of this paper is to show that the Cappadocian Fathers used Aristotle's notions of the first and second substance, in order to defend the original teachings of the church from the opposit teachings that were considered heretical. Even though Cappadocian theologians use philosophical notions in their work, this does not mean that they alienate from the original Christian teaching.
\end{abstract}

Keywords: Aristotle, God, hypostasis, Cappadocian Fathers, substance

Primljeno: 23.8.2020.

Prihvaćeno: 11.11.2020. 